eugenol, are proving valuable in the tropics. There was an important session on insect transmission of viruses, with the papers equally divided between entomologists and plant pathologists, and a detailed examination of the international and legal problems arising from insecticide residues. Advisory entomology, the United States technical assistance programmes, recent advances in insecticide application and the problems of special crops were also considered.

In the relatively small section on stored products entomology, the international problems arising from the variation in storage facilities and from the movement of insect-infested produce were examined by S. S. Easter (United States) and J. A. Froeman (Great, Britain). Contributions by R. W. Howe (Great Britain) on the potential range and importance of the Khapra beetle, and by H. M. Armitage (United States) on methods of eradication, proved to be of such general interest that an additional session was organized. Other papers described new methods of detecting hidden infestation in grain, new fumigation tech niques, and problems of storage in warm climates.

In the section on medical and veterinary entomology, symposia were held on the entomology of filarial infections, on animal viruses in arthropods, and on the biology and control of blackflies. In the first two the speakers concentrated on the arthropod vectors, what happens in them when infected, their biology and how this affects epidemiology. The blackfly papers reported advances made in Africa, Central America, the United States, Canada and Great Britain. Malaria and its vectors were discussed in papers from the World Health Organization and from India, Africa, Vietnam, Timor and elsewhere. Other papers on vectors and disease dealt with mites and scrub typhus in Malaya, ticks and tick paralysis in Canada, and problems resulting from the development of water resources in the United States. There were small groups of papers on the biology of cattle warbles and their control with systemic insecticides, on Phlebotomus, and on techniques for artificial feeding of blood-sucking arthropods. Other contributions of note concerned the periodicity of bitingfly attack in the U.S.S.R. and in Africa, and the transmission of blood parasites of ducks by Culicoides and of snakes by the mite Ophionyssus.

The discussions on apiculture ranged over nectar secretion, the composition of honey, and the behaviour, physiology and diseases of bees. A series of papers considered the pollination of fruit and logume erops by Apis and wild bees. R. Chauvin (France) reported that intra-muscular injection of royal jelly in man induced neutropenia and reticulocytosis, accompanied by a pronounced euphoria. Some $200 \mathrm{kgm}$. of royal jelly is harvested annually in France for therapeutic use.

I am greatly indebted to the leaders of the sections for assistance in compiling the foregoing account.

At the closing session of the Congress, Prof. A. da Costa Lima, of Brazil, and Dr. J. Chester Bradley, of the United States, were elected honorary members. Mr. N. D. Riley resigned as secretary of the Permanent Committee, and Dr. D. J. Kuenen, of the Netherlands, was elected in his place. It was decided to hold the eleventh congress in Vienna in 1960.

The Proceedings of the Congress, which will include most of the papers presented, will be published shortly. Inquiries should be addressed to J. A. Downes at the Science Service Building, Ottawa, Canada.

\section{CAMBRIDGE OBSERVATORIES}

\author{
REPORT FOR 1955
}

$T$ HE report of the Observatories Syndicate of the University of Cambridge for the year ending September 30, 1955*, deals first with solar research, and under this heading reference is made to Dr. H. von Klüber's work in completing and discussing the interferometric photographs of the green coronal line 5303 A., made in co-operation with Dr. A. H. Jarrett, of the University of St. Andrews Observatory, at the total eclipse of June 30, 1954. From measurements made in the range $1 \cdot 05-1 \cdot 3$ solar radii, and interpreting the line widths as due entirely to thermal motions, temperatures of the corona were found around $2.2 \times 10^{6}$ to $5 \times 10^{6}{ }^{\circ} \mathrm{K}$., most of the values being near $2 \times 5 \times 10^{\circ}{ }^{\circ} \mathrm{K}$. The results were so encouraging that preparations were made to observe the June 20 , 1955, eclipse at Hingurakgoda, using more extensive equipment; but unfortunately clouds prevented any results of scientific value being obtained by any of the eclipse expeditions to Ceylon. Dr. D. E. Blackwell has completed measurement and reduction of the corona photographs obtained by him at the 1954 eclipse, and a first paper was ready for publication when the report was compiled.

Dr. von Klüber has discovered that the large Mount Wilson diffraction grating, which gives a measured resolving-power of about 600,000 in the fifth order, allows remarkably clear visual observations of a fine structure of Fraunhofer lines, consisting of shifts and distortions arising from the solar granulation. The effects are seen in varying degrees in nearly all lines of the solar spectrum, but are most conspicuous in the hydrogen lines. Examination of the fine structure, using an electro-optical shutter of the A.D.P. type, failed to detect any local magnetic fields, but Dr. von Klüber and Dr. B. E. J. Pagel have started further work on this question. Various other matters are referred to in the report under solar research, among which may be noticed the balloon project mentioned in earlier reports. Dr. D. W. Dewhirst and Dr. Blackwell, by arrangements made through the Royal Society for co-operation with the Royal Air Force, made four flights in 8 Lincoln aircraft, and photographed the Sun, through an open door, with a 7 -in. refractor. Owing to vibration, but still more to air disturbance set up by the machine, it does not appear that high-resolution photographs of the Sun are likely to be obtained from conventional aircraft.

In the section dealing with the 17-in. Schmidt telescope, reference is made to the work of Dr. Dewhirst, assisted by G. G. Yates and A. N. Argue, in searching with the instrument for discrete radio sources. Using blue-sensitive plates going to a limiting magnitude about $18 \cdot 5$, a small number of faint galaxies have been detected the positions of which agree with radio sources of small diameter, but otherwise no peculiar stellar or extragalactic object has been found in the positions given. In addition, photographs in the blue, and with a plate filter combination for $\mathrm{H} \alpha$, have given no evidence to support the idea that either Hii regions or clusters of galaxies are responsible for the majority of sources of large diameter. Workers at the Cavendish Labora. tory have found a significant correlation between the

- University of Cambridge. Report of the Observatories Syndicate for the Year ending 1955, September 30 . (Cambridge: The University, 1956.) 
positions of radio sources and those of known astronomical galaxies. Photography of a selected number of suspected galaxies from the international catalogues reveals that some show peculiar structure or are members of small clusters.

The erection of the 36 -in. reflector with adjustment and testing has been completed; the telescope was designed for use either at the prime focus, at $f / 4.5$ or at a fixed coudé focus, to which the light travels along the polar axis northwards, using a three-mirror combination giving $f / 18$ or $f / 30$. Mr. G. G. Yates designed a photoelectric stellar photometer embodying a quartz monochromator, which allows simultaneous measurement of the brightness of a star in three regions of wave-length which may be selected at will. The photometer will be used at the coudé focus of the 36 -in. telescope and was approaching completion when the report was compiled.

\section{NATIONAL PHYSICAL LABORATORY, TEDDINGTON}

\section{REPORT FOR 1955}

$\mathrm{T}$ HE annual report for 1955 of the National Physical Laboratory, Teddington*, describes the wide range of research and test work carried out during the year. It contains the report of the Executive Committee which was presented to the meeting of the General Board held on May 25, the annual open day of the Laboratory (see Nature, 177, 1151 ; 1956); a note by the then director, Sir Edward Bullard, describing his own individual researches and the publications of the administrative staff; and detailed individual reports, prepared by the respective superintendents, of the activities of the ten Divisions and Test House of the Laboratory. The frontispiece consists of a reproduction of the portrait (painted by Bernard Dunstan) of Sir Edward, which was presented to him by his colleagues on the occasion of his resignation of his appointment after serving as director since 1950, and which now hangs alongside portraits of previous directors in the large conference room of the Laboratory.

The Executive Committee reports that it again gave its attention, when reviewing the research programme, to the desirability of reducing the number of research items so that effort could be concentrated on new and important work. The increase in staff allotted to the Laboratory under the plan for a fiveyear limited expansion of the Department of Scientific and Industrial Research was allocated mainly to the Aerodynamics and Ship Divisions, and the personnel and much of the equipment of the Metal and Fatigue Group of the High Temperature Mechanical Properties Section were transferred to the Mechanical Engineering Laboratory, East Kilbride. Work on the site for the new Ship Hydrodynamics Laboratory at Feltham was commenced in March 1955, and the casting of the main tank sections were expected to be completed before the end of 1956. The tank will be 1,300 by 48 by $25 \mathrm{ft}$., and its carriage will have a maximum speed of $50 \mathrm{ft}$./sec. A steerage and storage basin, a new water tunnel, a workshop, foundry and machine shop facilities will also be provided.

- Department of Scientiflc and Industrial Research. National Physical Laboratory: Report for the Year 1955. Pp. viii $+110+7$ plates. (I.ondon: H.M.S.O.. 1956.) 58. net.
Two international symposia were held during 1955 at the Laboratory, one in March on "Boundary Layer Effects in Aerodynamics" and the other in September on "Cavitation in Hydrodynamics". The proceedings of the symposia on "Engineering Dimensional Metrology", held in October 1953, and on "Precision Electrical Measurements", held in November 1954, and four new booklets, Nos. 9-12, in the series "Notes on Applied Science", were published during the year. In addition, the proceedings of the 1953 symposium on "Automatic Digital Computation" was reprinted twice; No. 3 in the series of "Units and Standards of Measurement" was reprinted; and a total of no less than 156 scientific papers were contributed by members of the staff of the Laboratory to various journals and periodicals.

The two industrial and scientific liaison officers have continued to bring to the notice of industry the research and development proceeding in the Laboratory. More than sixty firms were visited, and special tours were arranged in Scotland and South Wales. 106 lectures were given by other members of the staff to scientific and similar organizations. The Laboratory exhibited several items at the Physical Society's annual exhibition of scientific instruments and apparatus, the Engineering and Marine Exhibition and the British Instrument Industries Exhibition. Visitors to the Laboratory included parties from the Soviet Academy of Sciences, the International Electrotechnical Commission and from the joint meeting of the Iron and Steel Institute with the American Society of Metals and the American Institute of Mining and Metallurgical Engineers. Sir Edward Bullard delivered the Scott Lectures at Cambridge, in which he reviewed existing knowledge of the interior of the Earth and the theory of the solid state used for extrapolating results obtained in the laboratory to the much higher pressures occurring in the interior of the Earth, and he represented the Department of Scientific and Industrial Research at the international symposium on the utilization of solar energy held in Phoenix, Arizona. Thirty-eight, members of the staff made official visits overseas, and details of these, with the usual lists of members of the general board, executive committee and sub-committees, the positions and names of the senior staff, and bibliographies of the publications of the director and members of the staff of the Divisions of the Laboratory, are included in the annual report.

The individual reports of the various sections of the Laboratory reveal that a wide range of interesting and important investigations has been undertaken. The greater part of the work of the Aerodynamics Division is devoted to fundamental research on behalf of the Ministry of Supply, and the range of problems continues to increase, largely because of the increasing speeds attained by aircraft and missiles. In addition to investigations of high-speed flow, however, many low-speed investigations of swept-back wings and of methods of boundary-layer control designed to provide increased lift were also carried out. Other work not connected with aeronautics was concerned with such problems as the stability of suspension bridges, television masts and other structures, air flow over the decks of ships and the design of wind tunnels.

The digital electronic universal computing engine (DEUCE), an improved version of the pilot model of the ACE (automatic computing engine), was installed 